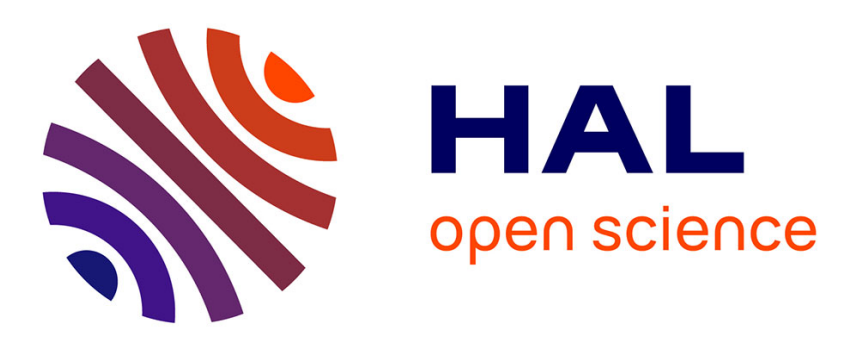

\title{
Shock microcycle of repeated-sprint training in hypoxia and tennis performance: Case study in a rookie professional player
}

Cyril Brechbuhl, Laurent Schmitt, Grégoire P Millet, Franck Brocherie

\section{- To cite this version:}

Cyril Brechbuhl, Laurent Schmitt, Grégoire P Millet, Franck Brocherie. Shock microcycle of repeatedsprint training in hypoxia and tennis performance: Case study in a rookie professional player. International journal of Sports Science and Coaching, 2018, 13 (5), pp.723-728. 10.1177/1747954118783586 . hal-02544893

\section{HAL Id: hal-02544893 https: / hal-insep.archives-ouvertes.fr/hal-02544893}

Submitted on 16 Apr 2020

HAL is a multi-disciplinary open access archive for the deposit and dissemination of scientific research documents, whether they are published or not. The documents may come from teaching and research institutions in France or abroad, or from public or private research centers.
L'archive ouverte pluridisciplinaire HAL, est destinée au dépôt et à la diffusion de documents scientifiques de niveau recherche, publiés ou non, émanant des établissements d'enseignement et de recherche français ou étrangers, des laboratoires publics ou privés. 


\section{International Journal of Sports Science \& Coaching}

\section{Shock microcycle of repeated-sprint training in hypoxia and tennis performance: case study in a rookie professional player}

\begin{tabular}{|c|c|}
\hline Journal: & International Journal of Sports Science \& Coaching \\
\hline Manuscript ID & SPO-17-0350.R2 \\
\hline Manuscript Type: & Original Article \\
\hline Date Submitted by the Author: & $n / a$ \\
\hline Complete List of Authors: & $\begin{array}{l}\text { Brechbuhl, Cyril; French Tennis Federation, National Technical Direction } \\
\text { Schmitt, Laurent; National Centre of Nordic-Ski, Department of Research } \\
\text { and Performance } \\
\text { Millet, Gregoire; Universite de Lausanne, ISSUL, Institute of Sport Sciences } \\
\text { Brocherie, Franck; French Institute of Sport (INSEP), Laboratory Sport, } \\
\text { Expertise and Performance (EA 7370), Research Unit }\end{array}$ \\
\hline Keywords: & $\begin{array}{l}\text { Tennis, Altitude, physical fitness, repeated-sprint ability, competition } \\
\text { period, block periodisation }\end{array}$ \\
\hline Abstract: & $\begin{array}{l}\text { The aim of this case study was to investigate the effects of a shock } \\
\text { microcycle of repeated-sprint training in hypoxia (RSH) on physical fitness } \\
\text { and tennis performance. One rookie professional tennis player performed } \\
\text { repeated-sprint ability (RSA) and Yo-Yo Intermittent Recovery level } 2 \\
\text { (YYIR2) tests before and after ( }+3 \text { days and }+21 \text { days) } 6 \text { sessions of RSH } \\
\text { ( } 4 \text { sets of } 5 \times \sim 6 \text { s repeated-shuttle sprint interspersed by } \sim 24 \mathrm{~s} \text { of passive } \\
\text { recovery) practiced during a 14-day "in-season" period. Tennis } \\
\text { performance was subjectively measured from match results and } \\
\text { Association of Tennis Professionals (ATP) points obtained during four } \\
\text { professional tournaments played before and after intervention. While no } \\
\text { changes were found at }+3 \text { days post-RSH, improvements in physical } \\
\text { fitness [single sprint time }(-4.5 \%), \text { RSA total time }(-3.1 \%) \text { and sprint } \\
\text { decrement }(-16.7 \%), \text { as well as YYIR } 2 \text { total distance covered }(+21.4 \%)] \\
\text { were observable at }+21 \text { days post-RSH. Tennis performance obtained } \\
\text { during the tournaments was better after intervention. From pre to post- } \\
\text { RSH, the decreases in opponents' ATP ranking during matches won }(1109 \\
\pm 334 \text { points vs. } 818 \pm 212 \text { points) and lost (499 } \pm 68 \text { points vs. } 256 \pm 58 \\
\text { points) revealed a stronger opposition. Consequently, a three-fold increase } \\
\text { (from } 4 \text { to } 12 \text { ATP points gained from pre to post-RSH) in participant's ATP } \\
\text { ranking was recorded. In summary, a } 14-\text { day "in-season" shock microcycle } \\
\text { including } 6 \text { sessions of repeated-sprint training in hypoxia revealed } \\
\text { interesting effects in specific fitness and tennis performance in a rookie } \\
\text { professional tennis player. }\end{array}$ \\
\hline
\end{tabular}




\section{Article type: Case study}

\section{Corresponding author:}

Dr Franck Brocherie Laboratory Sport, Expertise and Performance (EA 7370), Research Unit, French Institute of Sport (INSEP), 11 Avenue du Tremblay, Paris, France

Email: franck.brocherie@insep.fr

Phone: +33 (0)1 41744354

Article Title: Shock microcycle of repeated-sprint training in hypoxia and tennis performance: case study in a rookie professional player

Authors: Cyril Brechbuhl ${ }^{1,2}$, Laurent Schmitt ${ }^{2,3}$, Grégoire P. Millet ${ }^{2}$, Franck Brocherie ${ }^{4}$

${ }^{1}$ National Technical Direction, French Tennis Federation, Paris, France.

${ }^{2}$ ISSUL, Institute of Sport Sciences, Faculty of Biology and Medicine, University of Lausanne, Lausanne, Switzerland.

${ }^{3}$ Department of Research and Performance, National Centre of Nordic-Ski, Premanon, France.

${ }^{4}$ Laboratory Sport, Expertise and Performance (EA 7370), Research Unit, French Institute of Sport (INSEP), Paris, France.

Running title: RSH and tennis-specific performance

Number words: 240 for abstract, 2006 words from introduction to conclusion

\section{Number of figures: 2}

\section{Number of tables: 1}




\begin{abstract}
The aim of this case study was to investigate the effects of a shock microcycle of repeated-sprint training in hypoxia (RSH) on physical fitness and tennis performance. One rookie professional tennis player performed repeated-sprint ability (RSA) and Yo-Yo Intermittent Recovery level 2 (YYIR2) tests before and after (+3 days and +21 days) 6 sessions of RSH $(4$ sets of $5 \times \sim 6 \mathrm{~s}$ repeated-shuttle sprint interspersed by $\sim 24$ s of passive recovery) practiced during a 14-day "inseason" period. Tennis performance was subjectively measured from match results and Association of Tennis Professionals (ATP) points obtained during four professional tournaments played before and after intervention. While no changes were found at +3 days post-RSH, improvements in physical fitness [single sprint time (-4.5\%), RSA total time $(-3.1 \%)$ and sprint decrement $(-16.7 \%)$, as well as YYIR2 total distance covered $(+21.4 \%)]$ were observable at +21 days post-RSH. Tennis performance obtained during the tournaments was better after intervention. From pre to post-RSH, the decreases in opponents' ATP ranking during matches won $(1109 \pm 334$ points vs. $818 \pm 212$ points) and lost ( $499 \pm 68$ points $v s .256 \pm 58$ points) revealed a stronger opposition. Consequently, a three-fold increase (from 4 to 12 ATP points gained from pre to post-RSH) in participant's ATP ranking was recorded. In summary, a 14-day "in-season” shock microcycle including 6 sessions of repeated-sprint training in hypoxia revealed interesting effects in specific fitness and tennis performance in a rookie professional tennis player.
\end{abstract}

Keywords: Tennis, altitude, physical fitness, repeated-sprint ability, competition period, block periodization. 


\section{Introduction}

2 Tennis professional tour is characterized by a massive part of season dedicated to the competitions, 3 i.e., tournaments' participations. With this calendar, optimizing the training time appears 4 particularly determinant with a permanent search for the most specific and effective training

5 methods ${ }^{1}$. In order to overcome the limited time schedule, recent publications on intermittent sports 6 such as football ${ }^{2}$ or tennis ${ }^{3}$ have shown that the use of shock microcycles leads to sport-specific 7 performance improvements.

8 In this view, repeated-sprint training in hypoxia (RSH) has been proposed as a promising strategy in

9 intermittent sports to improve sport-specific performance ${ }^{4,5}$. For instance, Gatterer et al. ${ }^{6}$ reported 10 that repeated shuttle-run sprint training is feasible in a normobaric hypoxic chamber of limited size 11 (5 m width) and highlighted that a 12-days shock microcycle performed in hypoxia $(\sim 3300 \mathrm{~m})$ 12 provided a putative benefit on selected repeated-sprint outcomes (i.e., mean time) compared with 13 similar training in normoxia. This was further accompanied by similar gains in specific aerobic 14 fitness [i.e., Yo-Yo intermittent recovery test level 2 (YYIR2)] after both training modalities, 15 suggesting that RSH did not blunted aerobic adaptations ${ }^{6}$. Although one cannot rule out a placebo 16 effect leading to a higher motivation and/or higher training intensity than usually, suggested RSH17 related mechanisms were increased muscular perfusion, changed $\mathrm{pH}$ regulation and enhanced 18 glycolytic activity for repeated-sprint outcomes ${ }^{4}$, increased tissue oxygen extraction ${ }^{7}$, citrate 19 synthase activity and myoglobin content for YYIR2 ${ }^{4}$. Moreover, RSH has been consistently shown 20 as beneficial in different team sports [e.g., rugby ${ }^{8}$, field-hockey ${ }^{9}$ ] and leads to an increase in best 21 and mean repeated-sprint performance [for details, see ${ }^{10}$ ]. However, to date, no study has yet 22 investigated the effect of RSH on tennis performance.

23 Regarding the fitness determinants of professional tennis ${ }^{11}$, one may assume that RSH might 24 rapidly induce beneficial adaptations and performance improvement. Therefore, the aim of this case 
25 study was to investigate the effects of RSH intervention (6 sessions) over a 14-day "in-season" period on specific fitness and tennis performance in a rookie professional tennis player.

\section{Case report}

Participant

An 18-year-old rookie professional tennis player (classified in the top-10 of the combined Junior ranking of the International Tennis Federation during the season preceding the present study; body weight $67.0 \mathrm{~kg}$; stature $179 \mathrm{~cm}$; BMI $20.9 \mathrm{~kg} . \mathrm{m}^{-2}$ ) voluntarily agreed to participate. At the time of the investigation, he had been training competitively for the past 8 years, and regularly participated in 8-12 training sessions per week (total training hours per week of $12-25 \mathrm{~h}$ ) in a program that varies with the schedule of upcoming competition. The participant was informed of the experimental risks and gave his written voluntary informed consent for the tests and for the public reporting of his results. The study conformed to the Declaration of Helsinki, and was approved by the institutional review board.

\section{Time line}

All tests (see below) were performed prior to onset of RSH training (pre), after 14 days of intervention ( +3 days) and following 2 weeks of tournaments participation $(+21$ days $)$. Experimental intervention is described in Figure 1. Compared to pre- and post-RSH intervention $(18.5 \pm 4.0 \mathrm{~h}$ and $17.0 \pm 1.0 \mathrm{~h}$, respectively), the participant was submitted to on overall training volume of $24 \pm 2.0 \mathrm{~h}$ during the shock microcycle. Tennis-specific fitness level was assessed using testing battery which was used routinely during participant follow-up. Further, in order to compare the impact on tennis performance, match results from four professional (i.e., ITF Futures) tournaments played before and after intervention were collected.

\section{Tennis-specific fitness tests}


51 Single straight-line $20 \mathrm{~m}$ sprint, repeated-sprint ability (RSA) $(8 \times 20 \mathrm{~m}-20 \mathrm{~s}$ recovery $)$ and

52 YYIR2 performances were tested as described elsewhere ${ }^{9}$. RSA was assessed using three scores: 53 the best sprint time $\left(\mathrm{RSA}_{\text {best }}\right)$, the total sprint time (i.e., sum of the eight sprints; $\left.\mathrm{RSA}_{\mathrm{TT}}\right)$ and the 54 sprint decrement score ${ }^{12}: \mathrm{S}_{\mathrm{dec}}(\%)=\left[\left(\mathrm{RSA}_{\mathrm{TT}} /\left(\mathrm{RSA}_{\text {best }} \times 8\right)-1\right] \times 100\right.$. During the YYIR2 test, the 55 test ended when the participant had failed to reach the finishing line in time for the second time and 56 the total distance was then recorded.

57

\section{Tennis performance}

To evaluate the tennis performance during professional (i.e., ITF Futures) tournaments, we considered the opponent's level [i.e., Association of Tennis Professionals (ATP) ranking] and the number of ATP points gained by the participant before and after RSH intervention. These two criteria are based on the ATP world tour ranking which is the conventional method of assessing the performance of professional tennis players. Briefly, points score is given to a player regarding the round reached during tournaments.

\section{Repeated-sprint training in hypoxia}

During the 14-day "in-season" intervention period, the participant included 6 RSH sessions in his usual training routine (Figure 1). Briefly, each RSH session lasted $\sim 1 \mathrm{~h}$, including a 20 -min warmup, repeated-sprint training routine, and a 10-min cooling-down period. Specifically, RSH sessions consisted of 4 sets of $5 \times \sim 6$ s repeated-shuttle sprint interspersed by $\sim 24$ s of passive recovery and were completed on an indoor synthetic tennis surface inside a $120 \mathrm{~m}^{2}$ normobaric hypoxic training room (b-Cat, Netherlands) where ambient air was mixed with nitrogen (from pressurized tanks) to reduce $\mathrm{FiO}_{2}$ to $\sim 14.5 \%$ in order to simulate an altitude of $3000 \mathrm{~m}$. Temperature and humidity were maintained at $\sim 21^{\circ} \mathrm{C}$ and $\sim 55 \%$ relative humidity. Participant was constantly reminded to exert "allout" effort in trying to reach peak acceleration and to maintain the highest possible running speed for every sprint bout. Heart rate (HR; Polar Electro Oy, Kempele, Finland), arterial oxyhemoglobin 
$77\left(\mathrm{SpO}_{2} ; \mathrm{GO} 2 \mathrm{TM}\right.$ Achieve 9570-A, Nonin, Plymouth, MN, USA) and blood lactate concentration 78 ([la]; Lactate Pro Analyser, Arkray Inc, Kyoto, Japan) were measured after each set (data not 79 presented) and at the end of each RSH session. Ratings of perceived exertion (RPE; 6-20 and 0-10 80 Borg scales), overall perceived discomfort, perceived lower-limb discomfort, and perceived 81 difficulty breathing (modified Borg CR10 scales) were collected at the end of each RSH sessions ${ }^{13}$. 82 RSH training loads were calculated as total session duration $\times$ session $\mathrm{RPE}^{14}$.

83

\section{Data analysis}

Absolute and relative (percentage differences between pre, +3 days and +21 days post-RSH) values are presented by descriptive statistics. Probabilities were also calculated to establish whether the true difference was lower than, similar to, or higher than the smallest worthwhile difference or change (SWC, $0.2 \times$ overall pooled SD per dependent variable). A qualitative effect descriptor was assigned according to the likelihood of the change exceeding the SWC: 50-74\% "possible", 75-94\% "likely", 95-99\% "very likely", >99\% "almost certainly" ${ }^{15}$. Effects where the $90 \%$ confidence interval overlapped simultaneously the substantially positive and negative thresholds were deemed "unclear".

\section{Results}

Physiological responses at the end of RSH sessions corresponded to an averaged $\mathrm{HR}, \mathrm{SpO}_{2}$ and [La] of $168 \pm 6 \mathrm{bpm} ; 87.8 \pm 1.0 \% ; 9.9 \pm 1.9 \mathrm{mmol} . \mathrm{L}^{-1}$, respectively. Session RPEs were $15.6 \pm$ $1.1 / 7.0 \pm 0.8 \mathrm{au}$, corresponding to training load of $935 \pm 68 / 418 \pm 50$ au. Overall perceived discomfort $(6.8 \pm 0.8 \mathrm{au})$, perceived lower-limb discomfort $(7.3 \pm 0.8 \mathrm{au})$ and difficulty breathing $(7.0 \pm 0.9 \mathrm{au})$ indicated "very severe" scores.

All specific fitness and tennis performance results are summarized in Table 1 and Figure 2.

While no positive changes were found at +3 days post-RSH, improvements in physical fitness [single sprint time $(-4.5 \%$, very likely greater than the SWC), RSA total time $(-3.1 \%$, almost 
103 certainly greater) and sprint decrement (-16.7\%, very likely greater), as well as total distance 104 covered during YYIR2 $(+21.4 \%$, almost certainly greater $)]$ were observable at +21 days post-RSH. 105 Tennis performance achieved during the tournaments was improved after intervention. From pre to 106 post-RSH, the decreases in opponents' ATP ranking during matches won (1109 \pm 334 points vs. $107818 \pm 212$ points; 100/0/0, almost certainly greater) and lost (499 \pm 68 points $v s .256 \pm 58$ points; 108 100/0/0, almost certainly greater) revealed a stronger opposition. Consequently, a three-fold 109 increase (from 4 to 12 ATP points gained from pre to post-RSH) in participant's ATP ranking was 110 recorded.

\section{Discussion}

113 The main finding of this case study is that a 14-day "in-season" shock microcycle including 6 114 sessions of RSH revealed interesting effects in specific fitness and tennis performance in a rookie 115 professional tennis player. Notably, gains in sport-specific fitness were observed 21 days after 116 cessation of additional RSH, whereas no change was noted 3 days after intervention. This may have 117 accompanied the greater tennis performance recorded during the professional tournaments played 118 after intervention (i.e., between +3 days and +21 days post-RSH).

119 Although training overreaching/overtraining's risk may exist, periodization of intensive sessions is 120 required to generate physiological adaptations and sport-specific performance enhancement ${ }^{16,17}$. 121 Here, the underperformance observed at +3 days suggests a temporary state of fatigue which was 122 compensated after sufficient recovery period (i.e., performance improvement at +21 days). These 123 delayed benefits are in line with the specific timing recommendations for the "classical" hypoxic 124 training methods (e.g., living high-training high or living high-training low) with a positive window 125 after 2-3 weeks of sea level training, after return from altitude training before a prime competition $126{ }^{18}$. Therefore, this recently developed ${ }^{7} \mathrm{RSH}$ method seems suitable and effective to improve tennis127 specific performance as previously demonstrated in various team-sports [rugby ${ }^{8}$, football ${ }^{6}$, field128 hockey $\left.{ }^{9}\right]$. 
129 While it appears in line with the findings of Gatterer et al. ${ }^{6}$ using similar shock microcycle and 130 exercise mode (i.e., 12-day repeated shuttle-sprint training in hypoxia), as well as with a recent 131 meta-analysis on the effects of RSH (vs. similar normoxic training) on normoxic sport-specific 132 performance ${ }^{10}$, it seems that the shuttle-sprinting mode used for RSH may play a different role than 133 straight-line sprinting mode on transient fatigue development. Based on our data, we assume that 134 the inclusion of change of direction with successive deceleration/acceleration phases during 135 repeated sprints is likely to increase the mechanical (i.e., stride patterns and/or leg stiffness) and 136 peripheral [i.e., active bi-articular leg and core muscles] demands resulting in greater metabolic load 137 (e.g., lactate accumulation) ${ }^{19}$. Overall, this may slightly have altered RSH tolerance ${ }^{13}$ without 138 compromising long-term physiological adaptations (i.e., upregulation of the glycolytic activity, 139 higher ability to resynthesize phosphocreatine and higher oxygen utilization) and physical fitness 140 enhancement ${ }^{4,9}$.

141 Despite our limited understanding of the dose-response relationships between the training load and 142 training-induced changes in physical fitness and tennis performance, the additional effects of RSH 143 on official tennis performance highlights its potential effectiveness to improve tennis fatigue 144 resistance ${ }^{20}$. The use of repeated shuttle sprints likely mimicking on-court movements could have 145 led to positive changes in match performance, with a possible transfer of fitness gains [i.e., RSA146 related outcomes, agility and power (not measured here) and aerobic capacity] on technical skill 147 (i.e., advanced shots and stroke efficiency maintenance). Without undermining the importance of 148 fitness attributes, tennis performance is multifactorial and integrates an array of complex physical, 149 physiological, cognitive and psychological processes ${ }^{21}$. As such, further tennis-related RSH 150 research is encouraged to employ robust performance measures and a multi-dimensional approach 151 to tennis performance. The inclusion of on-court tennis specific test ${ }^{22}$ and perceptual-cognitive 152 skills (e.g., anticipatory and decision-making capacities) deserve future examination.

153 From a practical point of view, this case report can be used as a handy script for tennis players 154 preparing for competition. Detailed and periodized repeated-sprint training in hypoxia (RSH) 
155 microcycle for 14-day "in-season" period is provided and can be used by staff involved in highly-

156 trained athletes. By focusing on RSH as described with combination of both conditioning and tennis

157 training, an increase in performance can be expected. In addition, relevant tests and related

158 reference values are provided for individual adjustments to be done according to the needs and

159 capacity analysis.

160

161

\section{Conclusion}

162 In summary, a 14-day "in-season" shock microcycle including 6 sessions of repeated-sprint training

163 in hypoxia revealed interesting effects in physical fitness and tennis performance in a rookie

164 professional tennis player. However, gains in physical fitness were observed 21 days after cessation

165 of the last session, while remaining unaltered or even negatively affected shortly (3 days) post-

166 intervention. The long-term effect on specific fitness suggests a greater fatigue resistance which

167 may have resulted in greater tennis performance after intervention. Future investigations on special

168 focused hypoxic training block periodization in intermittent sports are warranted.

170 Acknowledgements

171 The authors would like to sincerely thank the player for participating in this case study and

172 consenting to its publication.

173

174 Declaration of Conflicting Interests

175 No potential conflict of interest was reported by the authors.

176

177 Funding

178 The authors have no sources of funding to disclose.

\section{References}


1

2

3

4

5

6

7

8

9

1. Fernandez-Fernandez J, Sanz-Rivas D, Sanchez-Munoz C, et al. Physiological Responses to On-Court vs Running Interval Training in Competitive Tennis Players. J Sports Sci Med 2011; 10: 540-545. 2011/01/01. 2. Christensen PM, Krustrup P, Gunnarsson TP, et al. VO2 kinetics and performance in soccer players after intense training and inactivity. Med Sci Sports Exerc 2011; 43: 1716-1724. DOI: 10.1249/MSS.0b013e318211c01a.

3. Fernandez-Fernandez J, Sanz-Rivas D, Sarabia JM, et al. Preseason Training: The Effects of a 17-Day High-Intensity Shock Microcycle in Elite Tennis Players. J Sports Sci Med 2015; 14: 783-791.

4. Faiss R, Girard $\mathrm{O}$ and Millet GP. Advancing hypoxic training in team sports: from intermittent hypoxic training to repeated sprint training in hypoxia. British journal of sports medicine 2013; 47 Suppl 1: i45-50. Review 2013/12/07. DOI: 10.1136/bjsports-2013-092741.

5. Girard O, Amann M, Aughey R, et al. Position statement--altitude training for improving team-sport players' performance: current knowledge and unresolved issues. Br J Sports Med 2013; 47 Suppl 1: i8-16. 2013/12/07. DOI: 10.1136/bjsports-2013-093109.

192 6. Gatterer H, Klarod K, Heinrich D, et al. Effects of a 12-day maximal shuttle-run shock microcycle in

193

194 hypoxia on soccer specific performance and oxidative stress. Applied physiology, nutrition, and metabolism = Physiologie appliquee, nutrition et metabolisme 2015; 40: 842-845. Randomized Controlled Trial

Research Support, Non-U.S. Gov't 2015/07/28. DOI: 10.1139/apnm-2014-0479.

7. Faiss R, Leger B, Vesin JM, et al. Significant molecular and systemic adaptations after repeated sprint training in hypoxia. PLoS One 2013; 8: e56522. 2013/02/26. DOI: 10.1371/journal.pone.0056522 PONE-D-12-39698 [pii].

8. Galvin HM, Cooke K, Sumners DP, et al. Repeated sprint training in normobaric hypoxia. British journal of sports medicine 2013; 47 Suppl 1: i74-79. Randomized Controlled Trial

Research Support, Non-U.S. Gov't 2013/12/07. DOI: 10.1136/bjsports-2013-092826.

9. Brocherie F, Millet GP, Hauser A, et al. "Live High-Train Low and High" hypoxic training improves team-sport performance. Med Sci Sports Exerc 2015; 47: 2140-2149. 2015/02/11. DOI: 10.1249/MSS.0000000000000630.

10. Brocherie F, Girard O, Faiss R, et al. Effects of Repeated-Sprint Training in Hypoxia on Sea-Level Performance: A Meta-Analysis. Sports Med 2017. Review 2017/02/15. DOI: 10.1007/s40279-017-0685-3.

11. Pereira TJ, Nakamura FY, de Jesus MT, et al. Analysis of the distances covered and technical actions performed by professional tennis players during official matches. Journal of sports sciences 2017; 35: 361368. 2016/03/31. DOI: 10.1080/02640414.2016.1165858.

12. Girard O, Racinais S, Kelly L, et al. Repeated sprinting on natural grass impairs vertical stiffness but does not alter plantar loading in soccer players. Eur J Appl Physiol 2011; 111: 2547-2555. 2011/03/04. DOI: 10.1007/s00421-011-1884-5.

13. Brocherie F, Millet GP and Girard O. Psychophysiological Responses to Repeated-Sprint Training in Normobaric Hypoxia and Normoxia. Int J Sports Physiol Perform 2017; 12: 115-123. 2016/05/04. DOI: 10.1123/ijspp.2016-0052.

14. Foster C, Florhaug JA, Franklin J, et al. A new approach to monitoring exercise training. J Strength Cond Res 2001; 15: 109-115. 2001/11/16.

15. Batterham AM and Hopkins WG. Making meaninful inferences about magnitudes. Int J Sports Physiol Perform 2006; 1: 50-57.

16. Foster C. Monitoring training in athletes with reference to overtraining syndrome. Med Sci Sports Exerc 1998; 30: 1164-1168. 1998/07/15.

17. Schmitt L, Hellard P, Millet GP, et al. Heart rate variability and performance at two different altitudes in well-trained swimmers. Int J Sports Med 2006; 27: 226-231. 2006/03/17. DOI: 10.1055/s-2005865647 .

18. Millet GP, Roels B, Schmitt L, et al. Combining hypoxic methods for peak performance. Sports Med 2010; 40: 1-25. 2009/12/22. DOI: 10.2165/11317920-000000000-00000.

19. Brocherie F, Millet GP and Girard O. Neuro-mechanical and metabolic adjustments to the repeated anaerobic sprint test in professional football players. Eur J Appl Physiol 2015; 115: 891-903. 2014/12/08. DOI: 10.1007/s00421-014-3070-z. 
$23020 . \quad$ Smekal G, Pokan R, von Duvillard SP, et al. Comparison of laboratory and "on-court" endurance 231 testing in tennis. International journal of sports medicine 2000; 21: 242-249. Comparative Study 232 2000/06/15. DOI: 10.1055/s-2000-310.

233 21. Hornery DJ, Farrow D, Mujika I, et al. Fatigue in tennis: mechanisms of fatigue and effect on 234 performance. Sports Med 2007; 37: 199-212. 2007/03/01.

235 22. Brechbuhl C, Girard O, Millet GP, et al. On the Use of a Test to Exhaustion Specific to Tennis (TEST) 236 with Ball Hitting by Elite Players. PLoS One 2016; 11: e0152389. 2016/04/02. DOI: 237 10.1371/journal.pone.0152389.

\section{Conflict of interest}

239 The authors report no conflicting interests.

240

\section{Acknowledgments}

242 The authors would like to express their gratitude to the participant, who voluntary agreed to 243 contribute. 


\section{Figures Legend}

Figure 1. Overview of the 14-day "in-season" intervention and description of a typical session of repeated-sprint training in hypoxia (RSH).

Figure 2. Comparison of opponent's ATP rankings (A) and participant's ATP points gained (B) before (pre) and after (+21 days) 14 days "in-season" of repeated-sprint training in hypoxia (RSH) intervention. 
Figure 1. Overview of the 14-day "in-season" intervention and description of a typical session of repeatedsprint training in hypoxia (RSH).

$37 \times 16 \mathrm{~mm}(300 \times 300 \mathrm{DPI})$ 


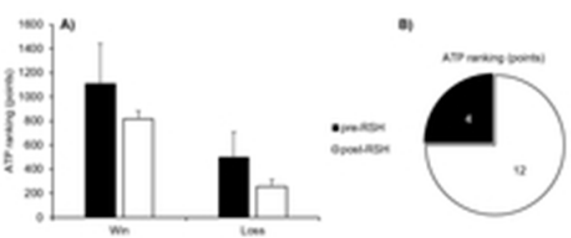

Figure 2. Comparison of opponent's ATP rankings (A) and participant's ATP points gained (B) before (pre) and after (+21 days) 14 days "in-season" of repeated-sprint training in hypoxia (RSH) intervention.

$19 \times 7 \mathrm{~mm}(300 \times 300 \mathrm{DPI})$ 
Table 1. Physical fitness results before (pre) and after ( +3 days and +21 days) 14 days "in-season" of repeated-sprint training in hypoxia $(\mathrm{RSH})$ intervention.

\begin{tabular}{|c|c|c|c|}
\hline & Pre & +3 days & +21 days \\
\hline Single sprint time (s) & 3.12 & 3.13 & 2.98 \\
\hline$\%$ of change from pre & & $+0.3 \%$ & $-4.5 \%$ \\
\hline$\%$ chances to be & & $39 / 39 / 22$ & $97 / 1 / 2$ \\
\hline greater/similar/smaller & & unclear & very likely \\
\hline than the SWC & & difference & greater \\
\hline $\mathrm{RSA}_{\text {best }}(\mathrm{s})$ & 3.10 & 3.13 & 3.02 \\
\hline$\%$ of change from pre & & $+1.0 \%$ & $-2.6 \%$ \\
\hline$\%$ chances to be & & $10 / 12 / 78$ & $96 / 1 / 3$ \\
\hline greater/similar/smaller & & unclear & very likely \\
\hline than the SWC & & difference & greater \\
\hline $\mathrm{RSA}_{\mathrm{TT}}(\mathrm{s})$ & 25.65 & 25.79 & 24.85 \\
\hline$\%$ of change from pre & & $+0.6 \%$ & $-3.1 \%$ \\
\hline$\%$ chances to be & & $0 / 11 / 89$ & $100 / 0 / 0$ \\
\hline greater/similar/smaller & & trivial & almost certainly \\
\hline than the SWC & & difference & greater \\
\hline$S_{\text {dec }}(\%)$ & 3.43 & 3.00 & 2.86 \\
\hline$\%$ of change from pre & & $-12.6 \%$ & $-16.7 \%$ \\
\hline$\%$ chances to be & & $96 / 2 / 2$ & $98 / 1 / 1$ \\
\hline greater/similar/smaller & & very likely & very likely \\
\hline than the SWC & & greater & greater \\
\hline YYIR2 distance (m) & 560 & 440 & 680 \\
\hline$\%$ of change from pre & . & $-21.4 \%$ & $+21.4 \%$ \\
\hline$\%$ chances to be & & $0 / 0 / 100$ & $100 / 0 / 0$ \\
\hline $\begin{array}{l}\text { greater/similar/smaller } \\
\text { than the SWC }\end{array}$ & & $\begin{array}{c}\text { most certai } \\
\text { oreater }\end{array}$ & almost certainly \\
\hline
\end{tabular}

